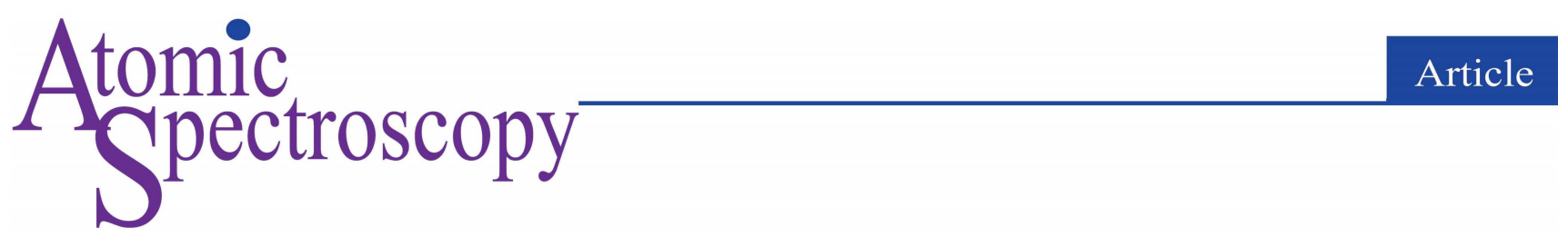

\title{
Influence of Spot Size on LA-ICP-MS Ablation Behavior for Synthetic Calcium Tungstate and Silicate Glass Reference Material NIST SRM 610
}

\author{
Yuting Xiao, ${ }^{a}$ Jian Yang, ${ }^{\mathrm{a}}$ Jun Deng, ${ }^{\mathrm{a}}$ Wei Wang, ${ }^{\mathrm{a}}$ Yuqiu Ke, ${ }^{\mathrm{a}, \mathrm{b}, *}$ and Yijian Sun ${ }^{\mathrm{a}, *}$ \\ a Faculty of Materials Metallurgy and Chemistry, Jiangxi University of Science and Technology, Ganzhou 341000, P.R. China \\ b Center of Analysis and Testing, Jiangxi University of Science and Technology, Ganzhou 341000, P.R. China
}

Received: November 23, 2020; Revised: December 08, 2020; Accepted: December 08, 2020; Available online: December 13, 2020.

DOI: 10.46770/AS.2021.01.006

ABSTRACT: Laser ablation behaviors are typically influenced by the laser operating parameters like the spot size, which has been well studied for silicate glass reference materials but not for samples, such as scheelite, which has the chemical composition of $\mathrm{CaWO}_{4}$. In this work, the ablation behaviors of synthetic $\mathrm{CaWO}_{4}$ single crystal $\mathrm{CaW}-1$ were studied and compared with those of the well-studied NIST SRM 610 silicate glass reference material. The results showed that LA-ICP-MS analysis of both the CaW-1 and NIST SRM 610 can obtain desired ablation craters and expected signal intensity ratios $(R)$ with a spot size of 60,44 , or 32 $\mu \mathrm{m}$, while it is not possible with the spot size of 10,16 , or even 90 $\mu \mathrm{m}$ due to the tapered craters or below-expected ablation efficiency/aerosol transport efficiency. Elemental fractionation was found for both CaW-1 and NIST SRM 610 at the small spot size. A spot size of $\geq 32 \mu \mathrm{m}$ is preferred for $\mathrm{CaW}-1$, and even for scheelite regardless of pulse number, while a spot size of $16 \mu \mathrm{m}$ is desirable for NIST SRM 610 with the pulse number of 200, but a spot size of $44 \mu \mathrm{m}$ is recommended as the pulse number increases to 300 .

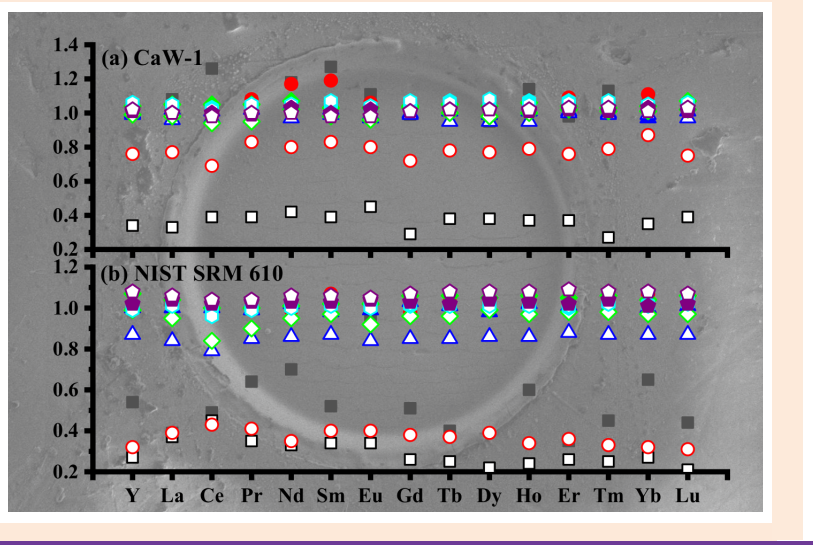

\section{INTRODUCTION}

Laser ablation-inductively coupled plasma-mass spectrometry (LA-ICP-MS) has become a widespread technology used for direct solid sample analysis. It not only has the advantages of ICPMS, such as high sensitivity, low limit of detection and full elemental coverage, but also offers the capability of high spatial resolution in situ microanalysis. ${ }^{1-7}$ Besides, there is no need for the preparation of sample solutions, thus avoiding contamination and reducing polyatomic ion interferences $\left(\right.$ e.g. ${ }^{140} \mathrm{Ce}^{16} \mathrm{O}^{+}$on ${ }^{156} \mathrm{Gd}^{+}$, ${ }^{60} \mathrm{Ni}^{40} \mathrm{Ar}^{+}$on $\left.{ }^{100} \mathrm{Ru}^{+}\right) \cdot{ }^{8-12}$

However, elemental fractionation is a significant issue for LAICP-MS because it can induce analytical errors. This fractionation may result from matrix effects related to laser-sample interactions, aerosol transport processes, and processes occurring in the ICP-
MS (e.g. aerosol ionization and subsequent ion extraction). To minimize laser-induced elemental fractionation, various technical approaches have been proposed after conducting experimental research on LA-ICP-MS ablation behaviors, such as investigating the morphology of ablation craters and aerosol particles, redesigning ablation cell geometry, optimizing transport tube materials, and performing comparative studies of infrared femtosecond lasers and ultraviolet nanosecond lasers. ${ }^{13-17}$ Besides, the laser operating conditions, such as spot size, repetition rate, fluence, pulse duration and energy, have been well studied for silicate glass samples or reference materials (e.g. NIST SRM 610). ${ }^{18-22}$

Scheelite is a common accessory mineral that has the chemical composition of $\mathrm{CaWO}_{4}$. It forms in various types of hydrothermal deposits and always incorporates abundant trace elements, such as 
the rare earth elements (REEs) of $\mathrm{Nb}, \mathrm{Pb}$ and $\mathrm{Mo}$, via substitution for $\mathrm{Ca}^{2+}$ or $\mathrm{W}^{6+}$ in the crystal lattice, which renders scheelite to exhibit distinct trace element geochemistry and thus serves as a fingerprint for deposit types, metallogenic settings and oreforming fluid compositions. ${ }^{23,}{ }^{24}$ As a result, it is essential to determine the elemental concentrations in scheelite accurately. To minimize analytical errors resulting from elemental fractionation, the matrix-matched calibration strategy is proposed. ${ }^{25-27}$ The matrix-matched calibration standard $\mathrm{CaW}-1$, which also has a matrix composition of $\mathrm{CaWO}_{4}$, has been synthesized in our previous work. ${ }^{28}$ However, due to the different physical properties and chemical composition between calcium tungstate and silicate glass, the laser ablation settings for silicate glass may not be suitable for LA-ICP-MS analysis of scheelite. For this reason and to further understand the ablation mechanisms of materials with different matrices, a systematic study of the ablation behaviors of scheelite is necessary.

The aim of this work is to investigate the influence of the LAICP-MS operating parameters and the spot size on the ablation behavior of scheelite. Because it has the same chemical composition as natural scheelite and a relatively homogeneous distribution of REEs, the $\mathrm{CaWO}_{4}$ calibration standard CaW-1 was selected as a representative sample of scheelite. The ablation behaviors, including signal intensity ratios (with and without internal standardization) and the elemental fractionation index (EFI) among different spot sizes, were systematically studied. For comparison, the laser ablation behaviors of CaW-1 were compared with those of the NIST SRM 610 silicate glass reference material under different spot sizes.

\section{EXPERIMENTAL}

An Excimer 193 nm laser ablation system (MicroLas Laser System GmbH, Germany) coupled to an Agilent 7700x ICP-MS (USA) was used for the LA-ICP-MS analyses at the State Key Laboratory of Biogeology and Environmental Geology, China University of Geosciences (Wuhan). High purity He at a constant flow rate of $0.9 \mathrm{~L} \mathrm{~min}^{-1}$ was used in the ablation cell as the carrier gas and merged with argon (make-up gas) behind the ablation cell. The NIST SRM 610 silicate glass reference material was used for routine tuning to obtain the maximum signal intensity of ${ }^{89} \mathrm{Y}^{+}$, ${ }^{139} \mathrm{La}^{+},{ }^{157} \mathrm{Gd}^{+}$, and ${ }^{175} \mathrm{Lu}^{+}$and to maintain the ${ }^{238} \mathrm{U}^{+} / 232 \mathrm{Th}^{+}$ratio close to 1 to ensure low oxide formation. Low oxide production was assured by the $\mathrm{m} / \mathrm{z} 248 / 232$ ratio (representing ${ }^{232} \mathrm{Th}^{16} \mathrm{O}^{+} / 232 \mathrm{Th}^{+}$), which was consistently $<0.5 \%$. The optimized operating conditions and measurement parameters are summarized in Table 1. A repetition rate of $6 \mathrm{~Hz}$ and a fluence of $6 \mathrm{~J} \mathrm{~cm}^{-2}$ were used. Each analysis consisted of 10 seconds of background signal acquisition, followed by $\sim 32$ seconds of ablation. The LA-ICP-MS data processing, off-line selection and integration of the background and the analyte signals were performed using an in-house program, ICPMSDataCal. ${ }^{29}$ The
Table 1. Typical Operating Conditions of LA-ICP-MS

\begin{tabular}{ll}
\hline Laser ablation system & ArF excimer laser \\
Wavelength, $\mathrm{nm}$ & 193 \\
Pulse duration, $\mathrm{ns}$ & 15 \\
Energy density, $\mathrm{J} \mathrm{cm}{ }^{-2}$ & 6 \\
Repetition rate, $\mathrm{Hz}$ & 6 \\
Spot size, $\mu \mathrm{m}$ & $10,16,32,44,60,90$ \\
Pulse number & 200 \\
Carrier gas (He) flow rate, $\mathrm{L} \mathrm{min}^{-1}$ & 0.9 \\
ICP-MS instrument & Agilent $7700 \mathrm{x}$ \\
RF power, W & 1550 \\
Auxiliary gas (Ar) flow rate, $\mathrm{L} \mathrm{min}^{-1}$ & 1.05 \\
Plasma gas (Ar) flow rate, $\mathrm{L} \mathrm{min}{ }^{-1}$ & 15 \\
Dwell time per isotope, ms & ${ }^{50}$ \\
Sampling depth, mm & ${ }^{7.5}$ \\
Detector mode & $\mathrm{Dual}$ \\
Measured isotopes & ${ }^{44} \mathrm{Ca},{ }^{89} \mathrm{Y},{ }^{139} \mathrm{La},{ }^{140} \mathrm{Ce}$, \\
& ${ }^{141} \mathrm{Pr},{ }^{146} \mathrm{Nd},{ }^{147} \mathrm{Sm}$, \\
& ${ }^{153} \mathrm{Eu},{ }^{157} \mathrm{Gd},{ }^{159} \mathrm{~Tb}$, \\
& ${ }^{163} \mathrm{Dy}, \quad{ }^{165} \mathrm{Ho},{ }^{166} \mathrm{Er}$, \\
& ${ }^{169} \mathrm{Tm},{ }^{172} \mathrm{Yb},{ }^{175} \mathrm{Lu}$ \\
\hline
\end{tabular}

morphology of the ablation craters was investigated using a Hitachi SU8010 field emission scanning electron microscope (FESEM) at the State Key Laboratory of Biogeology and Environmental Geology, China University of Geosciences (Wuhan). ${ }^{30}$

The NIST SRM 610 silicate glass reference material was purchased from the National Institute of Standards and Technology (NIST), USA. ${ }^{31}$ Synthetic $\mathrm{CaWO}_{4}$ single crystal CaW-1 with homogeneous distribution of REEs was prepared using the Czochralski technique and is discussed in our previous work. ${ }^{28}$ Accordingly, a multi-REE-doped $\mathrm{CaWO}_{4}$ single crystal was grown at the Jiangxi University of Science and Technology, P.R. China. The crystal was prepared following a two-step procedure: First, polycrystalline materials by a solid-state reaction in a muffle furnace with stoichiometric $\mathrm{CaCO}_{3}, \mathrm{WO}_{3}, \mathrm{Na}_{2} \mathrm{CO}_{3}$ and rare earth element oxide (at a nominal concentration of $c a .250 \mu \mathrm{g}$ $\mathrm{g}^{-1}$ ) were prepared; second, the polycrystalline materials were heated up to $c a \cdot 1630{ }^{\circ} \mathrm{C}$ (power: $4750 \mathrm{~W}$ ) and kept at this temperature for $2 \mathrm{~h}$. The crystal was grown using a-cut pure $\mathrm{CaWO}_{4}$ seeds at a pulling rate of $1 \mathrm{~mm} \mathrm{~h}^{-1}$ and a rotation rate of 6 rpm. The as-grown $\mathrm{CaWO}_{4}$ single crystal was named $\mathrm{CaW}-1$. Both samples, the CaW-1 and NIST SRM 610, were analyzed with a spot size of $10,16,32,44,60$, and $90 \mu \mathrm{m}$, respectively, for the comparative investigation of the influence of spot size on lasersample interactions.

\section{RESULTS AND DISCUSSION}

\section{Signal intensity ratios}

Signal sensitivity as a crucial parameter for the accurate quantification in LA-ICP-MS is matrix-dependent and, therefore, causes significant elemental fractionation in different samples. 
Moreover, laser-induced fractionation may arise under small spot size conditions. ${ }^{32}$ For these reasons, the influence of spot size on laser ablation was investigated for $\mathrm{CaWO}_{4}$ single crystal CaW-1 and silicate glass reference material NIST SRM 610 with a repetition rate of $6 \mathrm{~Hz}$ and a fluence of $6 \mathrm{~J} \mathrm{~cm}^{-2}$.

In theory, the ablation crater is circular and its volume can be calculated according to Equation 1:

$$
\left.V=\pi r^{2} h \quad \text { (Eq. } 1\right)
$$

where $V$ is the volume of the ablation crater, $r$ is the radius of the ablation crater (i.e., half of the spot size), and $h$ is the height/depth of the crater. For the same samples, the matrix composition remains unchanged and the ablated mass $(m)$ can also be calculated based on the density $(\rho)$ of the sample according to Equation 2:

$$
m=V \rho \quad \text { (Eq. 2) }
$$

As the sensitivity $(S)$ keeps constant for one homogeneous sample, the signal intensity can be calculated in Equation 3 as follows:

$$
I=m S \quad \text { (Eq. 3) }
$$

Under the same operating conditions, except for spot size, $h, \rho$, and $S$ were theoretically treated as constant for one sample, and then under different conditions of spot size, the ratio $(R)$ of intensity $I$ can be obtained with Equation 4 as follows:

$$
R_{a-b}=\frac{I_{a}}{I_{b}}=\frac{\pi r_{a}^{2} h \rho S}{\pi r_{b}^{2} h \rho S}=\frac{r_{a}^{2}}{r_{b}^{2}}
$$

where $r_{\mathrm{a}}$ and $r_{\mathrm{b}}$ are the radii of the ablation craters (i.e., half of the spot size) and the subscripts $a$ and $b$ represent the values of the spot size.

As listed in Table 2, the theoretical values of the signal intensity ratio $(R)$ were calculated according to Eq. 4 . For CaW-1, it was found that the experimental values of $R_{60-44}(1.77 \sim 1.85)$ and $R_{44-32}$ (1.87 1.97) for all REEs mainly agreed with the theoretical values (1.86 for $R_{60-44}$ and 1.89 for $R_{44-32}$ ). This demonstrates that the crater shapes for 60,44 , and $32 \mu \mathrm{m}$ are mainly regular (cylindrical or proportionally changed), and the volume of the ablated materials can be calculated according to Eq. 1. By contrast, the experimental values of $R_{32-16}(4.10 \sim 4.59)$ were a little higher than the theoretical value ( 4.00 for $R_{32-16}$ ). Since the crater shape for 32 $\mu \mathrm{m}$ was found to be regular, the reason for higher experimental values of $R_{32-16}$ can be ascribed to the lower signal intensity of 16 $\mu \mathrm{m}\left(I_{16}\right)$ due to the tapered crater and, therefore, a smaller crater volume and less ablated materials. This phenomenon was further verified for $R_{16-10}$ as disproportional and less materials were ablated from the sample, and a more seriously tapered crater was found for $10 \mu \mathrm{m}\left(I_{10}\right)$, which renders the experimental values (3.01 3.47) much larger than the theoretical value (2.56). Surprisingly, the experimental values of $R_{90-60}(1.76 \sim 1.83)$ were much lower than the theoretical value (2.25). The reason for this is unclear, but we speculate that the ablation efficiency or aerosol transport efficiency for $90 \mu \mathrm{m}$ may not reach the expected value because a large number of aerosol particles may accumulate in front of the sample or within the trench, which led to shielding as reported. ${ }^{33}$ It thus resulted in lower signal intensity $\left(I_{90}\right)$ and lower $R 90-60$ when the spot size of $90 \mu \mathrm{m}$ was employed, which may be corrected by increasing the gas flow rate, but it needs further studies to verify. Based on these results, it can be concluded that a spot size of 60,44 , or $32 \mu \mathrm{m}$ is desired for LA-ICP-MS analysis of the $\mathrm{CaWO}_{4}$ single crystal, while 16,10 , and even $90 \mu \mathrm{m}$ are unfavorable spot sizes due to the tapered craters or the belowexpected ablation efficiency/aerosol transport efficiency.

For silicate glass reference material NIST SRM 610, similar results as described above were found. The experimental values of $R_{60-44}(1.85 \sim 1.94)$ and $R_{44-32}(1.95 \sim 2.04)$ for all REEs mainly agreed with the theoretical values ( 1.86 for $R_{60-44}$ and 1.89 for $R_{44}$ 32 ), which further indicates that the crater shapes for 60,44 , and 32 $\mu \mathrm{m}$ are regular and the volume of ablated materials can be calculated according to Eq. 1. However, the experimental values of $R_{32-16}(5.65 \sim 6.10)$ and $R_{16-10}(3.39 \sim 4.03)$ were much higher than the theoretical value ( 4.00 for $R_{32-16}$, and 2.56 for $R_{16-10}$ ). This can

\begin{tabular}{|c|c|c|c|c|c|c|c|c|c|c|c|c|c|c|c|c|c|}
\hline Sample & $\begin{array}{c}\text { Signal } \\
\text { intensity } \\
\text { ratio }(R)\end{array}$ & $\begin{array}{c}\text { Theoretical } \\
\text { value }\end{array}$ & $\mathbf{Y}$ & $\mathbf{L a}$ & $\mathrm{Ce}$ & Pr & Nd & Sm & $\mathbf{E u}$ & Gd & $\mathbf{T b}$ & Dy & Ho & $\mathbf{E r}$ & $\mathbf{T m}$ & $\mathbf{Y b}$ & Lu \\
\hline Synthetic & $R_{90-60}$ & 2.25 & 1.76 & 1.77 & 1.75 & 1.79 & 1.78 & 1.76 & 1.78 & 1.79 & 1.78 & 1.78 & 1.77 & 1.80 & 1.80 & 1.83 & 1.77 \\
\hline \multirow{4}{*}{$\begin{array}{l}\mathrm{CaWO}_{4} \text { single } \\
\text { crystal CaW-1 }\end{array}$} & $R_{60-44}$ & 1.86 & 1.82 & 1.80 & 1.78 & 1.80 & 1.79 & 1.82 & 1.82 & 1.80 & 1.80 & 1.80 & 1.82 & 1.82 & 1.79 & 1.77 & 1.85 \\
\hline & $R_{44-32}$ & 1.89 & 1.89 & 1.92 & 1.95 & 1.92 & 1.94 & 1.89 & 1.92 & 1.87 & 1.93 & 1.92 & 1.92 & 1.97 & 1.92 & 1.89 & 1.88 \\
\hline & $R_{32-16}$ & 4.00 & 4.19 & 4.10 & 4.08 & 4.33 & 4.35 & 4.30 & 4.31 & 4.39 & 4.35 & 4.48 & 4.31 & 4.15 & 4.36 & 4.59 & 4.21 \\
\hline & $R_{16-10}$ & 2.56 & 3.27 & 3.01 & 3.15 & 3.06 & 3.12 & 3.16 & 3.01 & 3.05 & 3.14 & 3.22 & 3.16 & 3.16 & 3.44 & 3.23 & 3.47 \\
\hline NIST SRM & $R_{90-60}$ & 2.25 & 1.94 & 1.98 & 2.01 & 2.01 & 2.01 & 1.98 & 2.03 & 1.98 & 2.00 & 1.99 & 1.99 & 1.97 & 1.96 & 1.99 & 1.96 \\
\hline \multirow[t]{4}{*}{610} & $R_{60-44}$ & 1.86 & 1.94 & 1.91 & 1.85 & 1.88 & 1.90 & 1.91 & 1.87 & 1.91 & 1.92 & 1.90 & 1.92 & 1.94 & 1.93 & 1.91 & 1.92 \\
\hline & $R_{44-32}$ & 1.89 & 1.97 & 1.98 & 2.04 & 2.00 & 1.96 & 2.00 & 1.99 & 2.02 & 1.99 & 1.97 & 1.97 & 1.95 & 1.98 & 1.99 & 1.99 \\
\hline & $R_{32-16}$ & 4.00 & 5.77 & 5.67 & 5.76 & 5.70 & 5.92 & 5.65 & 5.98 & 5.74 & 5.92 & 5.91 & 5.95 & 6.10 & 6.07 & 6.03 & 6.05 \\
\hline & $R_{16-10}$ & 2.56 & 3.49 & 3.66 & 3.49 & 3.47 & 3.39 & 4.00 & 3.48 & 3.47 & 3.63 & 3.81 & 3.77 & 3.63 & 3.79 & 4.03 & 3.82 \\
\hline
\end{tabular}
be attributed to a lower signal intensity resulting from the tapered crater for $16 \mu \mathrm{m}\left(I_{16}\right)$ and $10 \mu \mathrm{m}\left(I_{10}\right)$, which is even

Table 2. Theoretical and Experimental Values of Signal Intensity Ratios $(R)$ Under Different Spot Sizes 

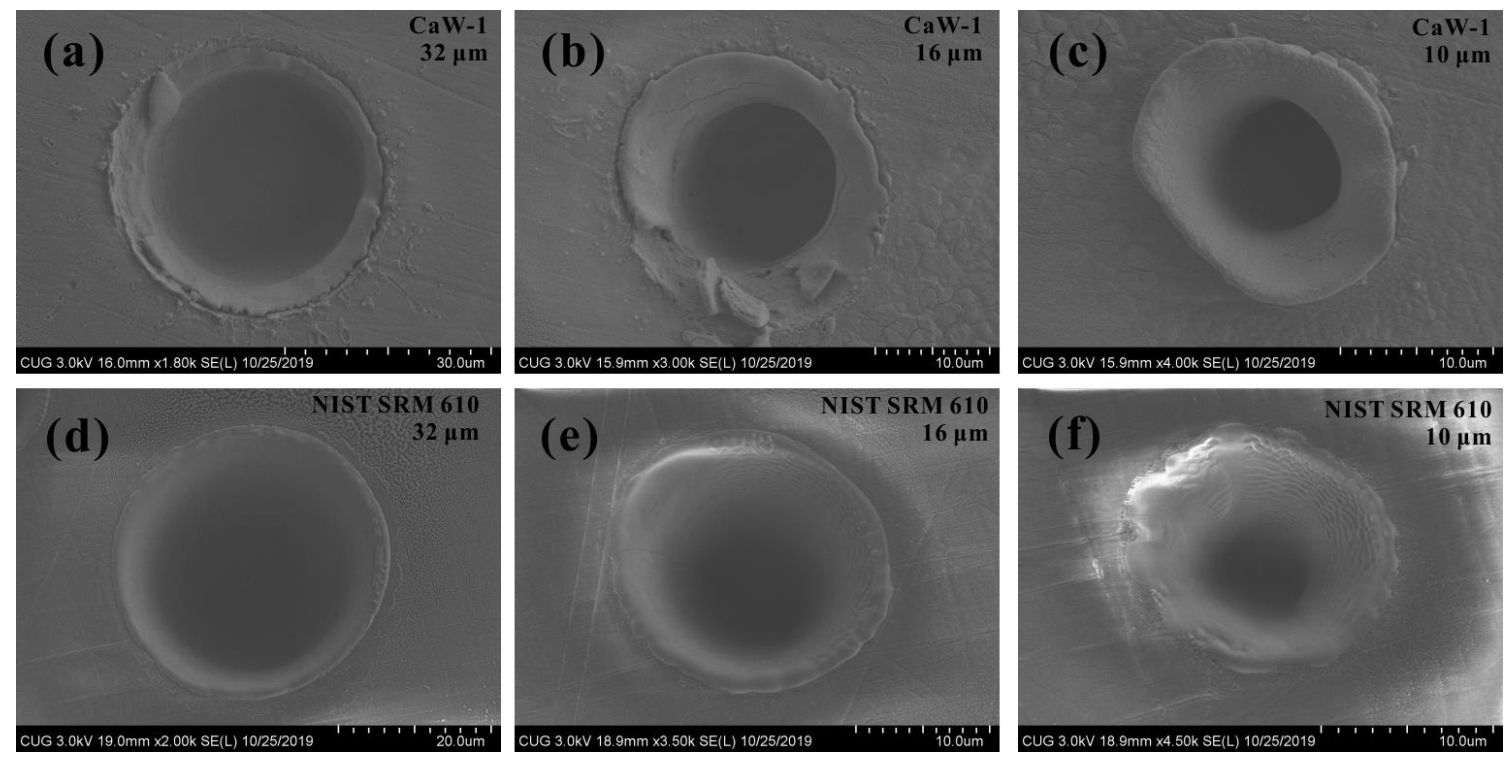

Fig. 1 SEM micrographs of laser ablation craters for CaW-1 (with a spot size of (a) $32 \mu \mathrm{m}$, (b) $16 \mu \mathrm{m}$, and (c) $10 \mu \mathrm{m}$ ) and NIST SRM 610 (with a spot size of (d) $32 \mu \mathrm{m}$, (e) $16 \mu \mathrm{m}$, and (f) $10 \mu \mathrm{m}$ ).

more severe than for the $\mathrm{CaWO}_{4}$ single crystal CaW-1. Furthermore, the experimental values of $R_{90-60}(1.94 \sim 2.03)$ were lower than the theoretical value (2.25), but a little higher than that of the $\mathrm{CaWO}_{4}$ single crystal CaW-1 (1.76 1.83). This demonstrates that different laser-sample interactions occurred for the $\mathrm{CaWO}_{4}$ single crystal vs. the NIST SRM 610 silicate glass, where for the latter more efficient laser ablation occurred, thus it reduced the exceptional phenomenon for $R_{90-60}$. In general, a spot size of 60,44 , or $32 \mu \mathrm{m}$ was desired for LA-ICP-MS analysis of the silicate glass sample, and the laser-sample interactions occurring for $\mathrm{CaWO}_{4}$ single crystal and NIST SRM 610 silicate glass were distinct.

The above-mentioned results for CaW-1 and NIST SRM 610 were verified by SEM micrographs of the laser ablation craters. Since the craters for both samples with a spot size of $90,60,44$, and $32 \mu \mathrm{m}$ are similar and regular, only the SEM micrograph of $32 \mu \mathrm{m}$ was displayed in Fig. 1 (a and d) to compare with those of 16 and $10 \mu \mathrm{m}$. As shown in Fig. 1, the most seriously and moderately tapered craters were found for $10 \mu \mathrm{m}$ (Fig. 1c and f) and $16 \mu \mathrm{m}$ (Fig. 1b and e), respectively. It led to an unsatisfactory ablation volume for 16 and $10 \mu \mathrm{m}$ and, thus, an undesired $R_{32-16}$ and $R_{16-10}$. In addition, rim growth around the craters due to the heat accumulation effect ${ }^{33}$ was found to be more obvious for $\mathrm{CaW}$ 1 (Fig. 1b and c) than for NIST SRM 610 (Fig. 1e and f), which indicates a slower heat transmission rate for $\mathrm{CaWO}_{4}$ single crystal than for NIST SRM 610 silicate glass. Moreover, more seriously tapered craters can be seen for NIST SRM 610 (Fig. 1e and f) compared to those of CaW-1 (Fig. $1 \mathrm{~b}$ and c). All of these phenomena are caused by matrix effects, which may induce analytical errors if NIST SRM 610 were used as the external standard to calibrate the elemental concentrations in $\mathrm{CaWO}_{4}$ single crystal and even scheelite.

\section{Internal standardization}

For LA-ICP-MS analysis, the internal standard can be used to calibrate the difference of the ablated material mass. The low abundance isotope of matrix elements (e.g., ${ }^{44} \mathrm{Ca}$ in calcite) is usually employed for this purpose. In this study, ${ }^{44} \mathrm{Ca}$ was employed as the internal standard, and the ratio $(R)$ of intensity $I$ was re-calculated to 1 according to Equation 5:

$$
R_{a-b}=\frac{I_{a}^{i} / I_{a}^{I S}}{I_{b}^{i} / I_{b}^{I S}}=\frac{\pi r_{a}^{2} h \rho S^{i} / \pi r_{a}^{2} h \rho S^{I S}}{\pi r_{b}^{2} h \rho S^{i} / r_{b}^{2} h \rho S^{I S}}=1
$$

where superscript $i$ represents element and $I S$ the internal standard (i.e. ${ }^{44} \mathrm{Ca}$ in this work).

As shown in Fig. 2, after internal standardization, the experimental values of $R$ were calculated to be approximately 1.00 independent of spot size. It indicates that ${ }^{44} \mathrm{Ca}$ can be used to compensate and calibrate the difference of the ablated material mass for both the $\mathrm{CaWO}_{4}$ single crystal and the NIST SRM 610 silicate glass. More importantly, it can be concluded that satisfactory results may also be obtained after internal standardization when different spot sizes must be selected for LAICP-MS analysis. For example, (a) a large spot size was preferential for real samples that contained very low concentrations or had a heterogenous distribution of the analytes to guarantee enough sensitivity and sampling representativeness, while a medium or small spot size is encouraged for external standards to protect the ICP-MS detector and to save valuable reference material. (b) A small spot size should be employed for the analysis of microfossils to obtain high spatial resolution, while a medium-to-small spot size is preferential for laser ablation on external standards for accurate quantification. (c) The laser beam focusing on the sample surface may vary each time for various reasons, which causes fluctuation of actual spot size on the 


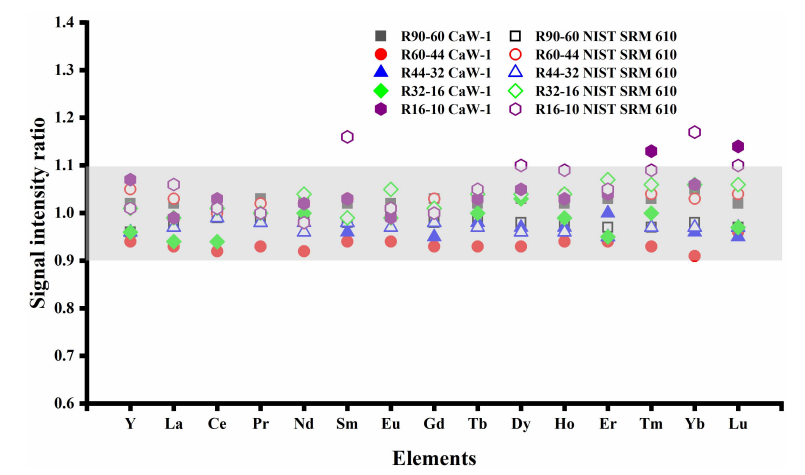

Fig. 2 Signal intensity ratios $(R)$ under different spot sizes after internal standardization with ${ }^{44} \mathrm{Ca}$.

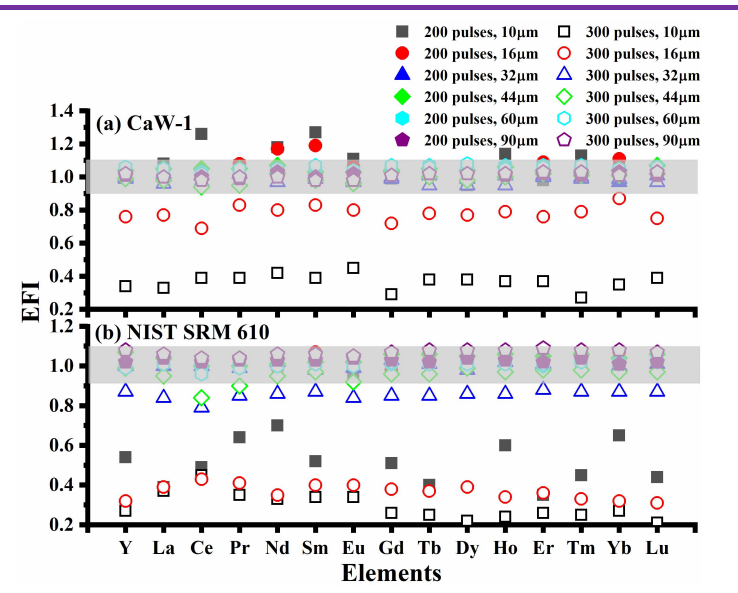

Fig. 3 Elemental fractionation index of REEs in CaW-1 (a) and NIST SRM 610 (b) under different spot size and pulse number.

sample surface. For these cases, the elemental fractionation possibly caused by different spot sizes and ablation material mass can be eliminated by internal standardization, which is significant for improving the results of LA-ICP-MS analysis. It should definitely be noted that in both samples the $R_{16-10}$ for some REEs (mainly for heavy REEs) was larger than 1.10, such as 1.13 for Tm and 1.14 for $\mathrm{Lu}$ in $\mathrm{CaW}-1$, and 1.16 for $\mathrm{Sm}, 1.17$ for $\mathrm{Yb}, 1.10$ for Dy and Lu in NIST SRM 610. From this perspective, a small spot size of $16 \mu \mathrm{m}$ is desirable, but an extremely small spot size $(10 \mu \mathrm{m})$ is not recommended for quantitative LA-ICP-MS analysis of $\mathrm{CaWO}_{4}$ single crystal (and even scheelite) and NIST SRM 610 silicate glass, even though internal standardization is performed.

\section{Elemental fractionation}

To further verify the influence of spot size on the ablation behavior of CaW-1 and NIST SRM 610, the elemental fractionation index (EFI) was calculated according to Equation 6 as set out by Fryer et al. ${ }^{34}$ :

$$
E F I=\left(\frac{I^{i}}{I^{I S}}\right)_{t_{2}} /\left(\frac{I^{i}}{I^{I S}}\right)_{t_{1}} \quad \text { (Eq. 6) }
$$

where $I^{i}$ and $I^{I S}$ are the intensity of element $i$ and the internal standard $I S$, respectively; $t_{1}$ and $t_{2}$ are the first $16 \mathrm{sec}$. and the second 16 sec. during each LA-ICP-MS analysis.

As listed in Table 3, it was found that the EFI remained constant (ca. 1.00) for CaW-1 when the spot size was larger than $32 \mu \mathrm{m}$. However, obvious elemental fractionation $(\mathrm{EFI}>1.10$ or $<0.90$ ) was found for $\mathrm{Ce}$ (1.26), $\mathrm{Nd}$ (1.18), $\mathrm{Sm}$ (1.27), $\mathrm{Eu}$ (1.11), Ho (1.14), and Tm (1.13) when a spot size of $10 \mu \mathrm{m}$ was used, which was also found for $\mathrm{Nd}$ (1.17), Sm (1.19), and $\mathrm{Yb}$ (1.11) when a spot size of $16 \mu \mathrm{m}$ was used. For NIST SRM 610, more severe elemental fractionation was found for almost all REEs (except Eu) as the EFI ranged from 0.20 for Dy to 0.70 for $\mathrm{Nd}$ when a spot size of $10 \mu \mathrm{m}$ was used, while elemental fractionation was hardly found when the spot size increased to larger than $16 \mu \mathrm{m}$. It indicates that a small spot size (i.e., $10 \mu \mathrm{m}$ ) is not suitable for quantitative LA-ICP-MS microanalysis of both the $\mathrm{CaWO}_{4}$ single crystal and the NIST SRM 610.

This was also confirmed by performing additional experiments with the same operating parameters, except for increasing the number of laser ablation pulses from 200 to 300. As shown in Fig. $3 \mathrm{a}$, when 300 pulses were performed on $\mathrm{CaW}-1$, a significant elemental fractionation was found with the spot sizes of $10 \mu \mathrm{m}$ and $16 \mu \mathrm{m}$ since the EFI were lower than 0.90 for all REEs. As for NIST SRM610 (Fig. 3b), when 300 pulses were used, more

Table 3. EFI for REEs in CaW-1 and NIST SRM 610 under Different Spot Sizes

\begin{tabular}{|c|c|c|c|c|c|c|c|c|c|c|c|c|c|c|c|c|}
\hline Sample & Spot size $(\mu \mathrm{m})$ & $\mathbf{Y}$ & $\mathbf{L a}$ & $\mathrm{Ce}$ & Pr & Nd & Sm & Eu & Gd & $\mathbf{T b}$ & Dy & Ho & Er & Tm & $\mathbf{Y b}$ & Lu \\
\hline \multirow[t]{6}{*}{ CaW-1 } & 10 & 1.02 & 1.08 & 1.26 & 1.07 & 1.18 & 1.27 & 1.11 & 0.99 & 1.06 & 0.95 & 1.14 & 0.98 & 1.13 & 1.05 & 1.04 \\
\hline & 16 & 1.02 & 1.02 & 0.99 & 1.08 & 1.17 & 1.19 & 1.06 & 1.04 & 1.06 & 1.06 & 1.04 & 1.09 & 1.06 & 1.11 & 1.05 \\
\hline & 32 & 1.00 & 1.02 & 1.01 & 1.02 & 1.05 & 1.02 & 0.99 & 1.00 & 1.01 & 0.99 & 1.01 & 1.01 & 1.00 & 0.97 & 1.01 \\
\hline & 44 & 1.04 & 1.05 & 1.05 & 1.05 & 1.07 & 1.03 & 1.03 & 1.04 & 1.05 & 1.04 & 1.06 & 1.04 & 1.03 & 1.01 & 1.07 \\
\hline & 60 & 1.03 & 1.03 & 1.03 & 1.04 & 1.02 & 1.05 & 1.03 & 1.04 & 1.07 & 1.06 & 1.07 & 1.07 & 1.06 & 1.04 & 1.04 \\
\hline & 90 & 1.01 & 1.00 & 1.00 & 0.99 & 1.03 & 1.00 & 1.02 & 1.01 & 1.02 & 1.02 & 1.01 & 1.02 & 1.01 & 1.03 & 1.01 \\
\hline NIST & 10 & 0.54 & 0.39 & 0.49 & 0.64 & 0.70 & 0.52 & 0.95 & 0.51 & 0.40 & 0.20 & 0.60 & 0.35 & 0.45 & 0.65 & 0.44 \\
\hline SRM & 16 & 1.01 & 1.02 & 1.01 & 1.01 & 0.99 & 1.07 & 1.03 & 0.98 & 1.03 & 1.02 & 1.04 & 0.99 & 1.02 & 1.07 & 1.01 \\
\hline \multirow[t]{4}{*}{610} & 32 & 1.00 & 1.00 & 1.00 & 0.99 & 1.02 & 0.98 & 0.99 & 1.03 & 1.01 & 0.98 & 1.02 & 1.01 & 1.00 & 1.00 & 1.01 \\
\hline & 44 & 1.07 & 1.04 & 1.00 & 1.00 & 1.01 & 1.02 & 1.02 & 1.06 & 1.06 & 1.05 & 1.06 & 1.05 & 1.06 & 1.04 & 1.06 \\
\hline & 60 & 1.01 & 1.02 & 1.00 & 1.00 & 1.01 & 1.03 & 1.01 & 1.01 & 1.01 & 1.02 & 1.02 & 1.00 & 1.02 & 1.01 & 1.02 \\
\hline & 90 & 1.02 & 1.04 & 1.02 & 1.03 & 1.03 & 1.03 & 1.04 & 1.03 & 1.02 & 1.04 & 1.03 & 1.02 & 1.04 & 1.01 & 1.02 \\
\hline
\end{tabular}


significant elemental fractionation was found for all REEs not only with the spot size of $10 \mu \mathrm{m}$, but also with the spot sizes of 16 and $32 \mu \mathrm{m}$. This can be attributed to the fact that more pulses increase the depth/diameter ratio of the ablation crater and, therefore, increase the down-hole fractionation. ${ }^{35,36}$ In conclusion, elemental fractionation is found for both the CaW-1 and the NIST SRM 610 under a small spot size, which becomes more severe when the number of laser ablation pulses increases due to down-hole fractionation. Combining the results as mentioned above, a spot size of $\geq 32 \mu \mathrm{m}$ is preferential for $\mathrm{CaW}-1$ and even scheelite regardless of pulse number, while a spot size of $16 \mu \mathrm{m}$ is desirable for NIST SRM 610 with the pulse number of 200 , but a spot size of $44 \mu \mathrm{m}$ is recommended as the pulse number increases to 300 .

\section{CONCLUSIONS}

In this work, comparative studies on the LA-ICP-MS ablation behaviors of silicate glass reference material NIST SRM 610 and synthetic calcium tungstate calibration standard CaW-1 were performed under different laser ablation spot sizes. LA-ICP-MS analysis on both the CaW-1 and NIST SRM 610 can obtain desired ablation craters and expected signal intensity ratios $(R)$ with a spot size of 60,44 , or $32 \mu \mathrm{m}$, while it is not possible with the spot size of 10,16 , and even $90 \mu \mathrm{m}$ due to the tapered craters or belowexpected ablation efficiency/aerosol transport efficiency. Besides, the difference of ablation material mass caused by different spot sizes can be eliminated by internal standardization as the values of $R$ were normalized to $c a$. 1.00 , except with an extremely small spot size. Elemental fractionation was found for $\mathrm{CaW}-1$ and NIST SRM 610 under the small spot size. A spot size of $\geq 32 \mu \mathrm{m}$ is preferential for CaW-1 and even scheelite regardless of pulse number, while a spot size of $16 \mu \mathrm{m}$ is desirable for NIST SRM 610 with the pulse number of 200 , but a spot size of $44 \mu \mathrm{m}$ is recommended as the pulse number increases to 300 .

\section{AUTHOR INFORMATION}

\section{Corresponding Author}

* Y.-Q. Ke

Email address: keyuqiu@cug.edu.cn

* Y.-J. Sun

Email address: sunyijian@jxust.edu.cn

\section{Notes}

The authors declare no competing financial interest.

\section{ACKNOWLEDGMENTS}

This work was supported by the National Natural Science Foundation of China (No. 41603025), the Natural Science Foundation of Jiangxi Province (No. 20192BAB203024, 20181BAB211009), the Research Foundation of the Education Bureau of Jiangxi Province of China (No. GJJ180428, GJJ180461, GJJ170546), and the PhD Research Startup Foundation of Jiangxi University of Science and Technology (No. jxxjbs17066, jxxjbs17041, jxxjbs17051).

\section{REFERENCES}

1. L. Guo, Q. Li, Y. Chen, G. Zhang, Y. Xu, and Z. Wang, J. Anal. At. Spectrom., 2020, 35, 1441-1449. https://doi.org/10.1039/d0ja00054j

2. P. Bohleber, M. Roman, M. Šala, and C. Barbante, J. Anal. At. Spectrom., 2020, 35, 2204-2212. https://doi.org/10.1039/D0JA00170H

3. Y. Zhu, C. Y. Li, M. Chen, G. X. Zhang, C. W. Mao, H. M. Kou, and Z. Wang, At. Spectrosc., 2019, 40, 49-54. https://doi.org/10.46770/AS.2019.02.003

4. Z. P. Yang, S. E. Jackson, L. J. Cabri, P. Wee, H. P. Longerich, and M. Pawlak, J. Anal. At. Spectrom., 2020, 35, 534-547. https://doi.org/10.1039/c9ja00285e

5. W. Guo, R. Wang, W. X. Wang, and Y. E. Peng, J. Food Compos. Anal., 2020, 91, 103517. https://doi.org/10.1016/j.jfca.2020.103517

6. H. Cui, W. Guo, L. L. Jin, Y. E. Peng, and S. H. Hu, J. Anal. At. Spectrom., 2020, 35, 592-599. https://doi.org/10.1039/c9ja00340a

7. W. Guo, L. L. Jin, S. H. Hu, and Q. H. Guo, J. Agric. Food Chem., 2017, 65, 3407-3413. https://doi.org/10.1021/acs.jafc.7b00535

8. W. Guo, S. H. Hu, J. A. Zhao, S. S. Jin, W. J. Liu, and H. F. Zhang, Microchem. J., 2011, 97, 154-159. https://doi.org/10.1016/j.microc.2010.08.003

9. Y. Q. Ke, J. Z. Zhou, L. Qiao, M. H. Zhang, W. Guo, L. L. Jin, and S. H. Hu, Anal. Methods, 2019, 11, 2129-2137. https://doi.org/10.1039/c8ay02664e

10. Y. T. Li, W. Guo, Z. C. Hu, L. L. Jin, S. H. Hu, and Q. H. Guo, J. Agric Food Chem., 2019, 67, 935-942. https://doi.org/10.46770/as.2018.01.001

11. W. Guo, S. H. Hu, X. J. Wang, J. Y. Zhang, L. L. Jin, Z. L. Zhu, and H. F. Zhang, J. Anal. At. Spectrom., 2011, 26, 1198-1203. https://doi.org/10.1039/c1ja00005e

12. X. Lin, W. Guo, L. L. Jin, and S. H. Hu, At. Spectrosc., 2020, 41, 1-10. https://doi.org/10.46770/as.2020.01.001

13. M. Hola, V. Konecna, P. Mikuska, J. Kaiser, and V. Kanicky, Spectrochim. Acta Part B, 2010, 65, 51-60. https://doi.org/10.1016/j.sab.2009.11.003

14. M. Hola, J. Ondracek, H. Novakova, M. Vojtisek-Lom, R. Hadravova, and V. Kanicky, Spectrochim. Acta Part B, 2018, 148, 193-204. https://doi.org/10.1016/j.sab.2018.07.001

15. R. Kovacs and D. Günther, J. Anal. At. Spectrom., 2008, 23, 1247-1252. https://doi.org/10.1039/b803789b

16. T. Luo, Y. Wang, M. Li, W. Zhang, H. H. Chen, and Z. C. Hu, At. Spectrosc., 2020, 41, 11-19. https://doi.org/10.46770/as.2020.01.002 
17. N. J. Saetveit, S. J. Bajic, D. P. Baldwin, and R. S. Houk, J. Anal. At. Spectrom., 2008, 23, 54-61. https://doi.org/10.1039/b709995a

18. F.-X. d'Abzac, F. Poitrasson, R. Freydier, and A.-M. Seydoux-Guillaume, J. Anal. At. Spectrom., 2010, 25, 681-689. https://doi.org/10.1039/b913584g

19. A. El Korh, Spectrochim. Acta Part B, 2013, 86, 75-87. https://doi.org/10.1016/j.sab.2013.04.009

20. T. Vaculovic, T. Warchilova, Z. Cadkova, J. Szakova, P. Tlustos, V. Otruba, and V. Kanicky, Appl. Surf. Sci., 2015, 351, 296-302. https://doi.org/10.1016/j.apsusc.2015.05.136

21. J. Fietzke and M. Frische, J. Anal. At. Spectrom., 2016, 31, 234-244. https://doi.org/10.1039/c5ja00253b

22. X. H. Liao, T. Luo, S. H. Zhang, W. Zhang, K. Q. Zong, Y. S. Liu, and Z. C. Hu, J. Anal. At. Spectrom., 2020, 35, 1071-1079. https://doi.org/10.1039/c9ja00404a

23. Y. Fu, X. M. Sun, H. Y. Zhou, H. Lin, L. Y. Jiang, and T. J. Yang, Ore Geol. Rev., 2017, 80, 828-837. https://doi.org/10.1016/j.oregeorev.2016.08.030

24. W. W. Zhao, M. F. Zhou, A. E. Williams-Jones, and Z. Zhao, Chem. Geol., 2018, 477, 123-136. https://doi.org/10.1016/j.chemgeo.2017.12.020

25. Y. Q. Ke, Y. J. Sun, P. J. Lin, J. Z. Zhou, Z. F. Xu, C. F. Cao, Y. Yang, and S. H. Hu, Microchem. J., 2019, 145, 642-647. https://doi.org/10.1016/j.microc.2018.11.016

26. A. Ugarte, N. Unceta, C. Pecheyran, M. A. Goicolea, and R. J. Barrio, J. Anal. At. Spectrom., 2011, 26, 1421-1427. https://doi.org/10.1039/c1ja10037h
27. M. V. Galiova, K. Stepankova, R. Copjakova, J. Kuta, L. Prokes, J. Kynicky, and V. Kanicky, J. Anal. At. Spectrom., 2015, 30, 1356-1368. https://doi.org/10.1039/c4ja00347k

28. Y. Ke, J. Zhou, X. Yi, Y. Sun, J. Shao, S. You, W. Wang, Y. Z. Tang, and C. Tu, J. Anal. At. Spectrom., 2020, 35, 886-895. https://doi.org/10.1039/D0JA00015A

29. Y. Liu, Z. Hu, S. Gao, D. Günther, J. Xu, C. Gao, and H. Chen, Chem. Geol., 2008, 257, 34-43.

https://doi.org/10.1016/j.chemgeo.2008.08.004

30. Y. H. Fang, Z. Q. Chen, S. Kershaw, H. Yang, and M. Luo, Global Planet. Change, 2017, 152, 115-128. https://doi.org/10.1016/j.gloplacha.2017.02.011

31. https://www.nist.gov

32. Z. Hu, Y. Liu, L. Chen, L. Zhou, M. Li, K. Zong, L. Zhu, and S. Gao, J. Anal. At. Spectrom., 2011, 26, 425-430. https://doi.org/10.1039/c0ja00145g

33. J. J. Gonzalez, A. Fernandez, D. Oropeza, X. Mao, and R. E. Russo, Spectrochim. Acta Part B, 2008, 63, 277-286. https://doi.org/10.1016/j.sab.2007.11.035

34. B. J. Fryer, S. E. Jackson, and H. P. Longerich, Can. Mineral., 1995, 33, 303-312.

35. T. Luo, Z. C. Hu, W. Zhang, Y. S. Liu, K. Q. Zong, L. Zhou, J. F. Zhang, and S. H. Hu, Anal. Chem., 2018, 90, 9016-9024. https://doi.org/10.1021/acs.analchem.8b01231

36. T. Luo, X. D. Deng, J. W. Li, Z. C. Hu, W. Zhang, Y. S. Liu, and J. F. Zhang, J. Anal. At. Spectrom., 2019, 34, 1439-1446. https://doi.org/10.1039/c9ja00139e 